\title{
Infection of equine monocyte-derived macrophages with an attenuated equine infectious anemia virus (EIAV) strain induces a strong resistance to the infection by a virulent EIAV strain
}

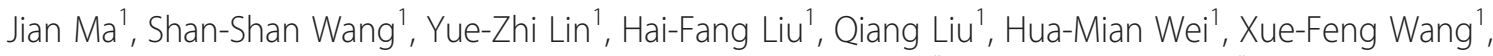 \\ Yu-Hong Wang ${ }^{2}$, Cheng Du', Xian-Gang Kong ${ }^{1}$, Jian-Hua Zhou ${ }^{1 *}$ and Xiaojun Wang ${ }^{1 *}$
}

\begin{abstract}
The Chinese attenuated equine infectious anemia virus (EIAV) vaccine has successfully protected millions of equine animals from EIA disease in China. Given that the induction of immune protection results from the interactions between viruses and hosts, a better understanding of the characteristics of vaccine strain infection and host responses would be useful for elucidating the mechanism of the induction of immune protection by the Chinese attenuated EIAV strain. In this study, we demonstrate in equine monocyte-derived macrophages (eMDM) that EIAV FDDV13, a Chinese attenuated EIAV strain, induced a strong resistance to subsequent infection by a pathogenic strain, EIAV $V_{U K 3}$. Further experiments indicate that the expression of the soluble EIAV receptor sELR1, Toll-like receptor 3 (TLR3) and interferon $\beta$ (IFNB) was up-regulated in eMDM infected with EIAV FDDV13 compared with eMDM infected with EIAV $V_{U K 3}$. Stimulating eMDM with poly I:C resulted in similar resistance to EIAV infection as induced by EIAV FDDV13 and was correlated with enhanced TLR3, sELR1 and IFN $\beta$ expression. The knock down of TLR3 mRNA significantly impaired poly I:C-stimulated resistance to EIAV, greatly reducing the expression of sELR1 and IFN $\beta$ and lowered the level of infection resistance

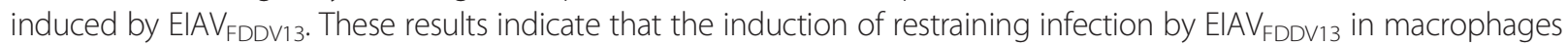
is partially mediated through the up-regulated expression of the soluble viral receptor and IFN $\beta$, and that the TLR3 pathway activation plays an important role in the development of an EIAV-resistant intracellular environment.
\end{abstract}

\section{Introduction}

Equine infectious anemia virus (EIAV) is an equine lentivirus with a tropism primary for monocyte/macrophage lineage in vivo [1,2]. The clinical manifestation of equine infectious anemia (EIA), which is caused by EIAV infection, can be divided into an acute phase, a chronic phase, and an asymptomatic phase. The acute and chronic phases exhibit typical viremia accompanied by a high fever, anemia, thrombocytopenia, edema, and weight loss. The infected equines usually enter the life-long asymptomatic carrier state after 8-12 months. However, the virus maintains a low level of stable replication in tissues that are enriched

\footnotetext{
* Correspondence: Jianhua_uc@126.com; xjw@hvri.ac.cn

'State Key Laboratory of Veterinary Biotechnology, Harbin Veterinary Research Institute, Chinese Academy of Agricultural Sciences, Harbin, Heilongjiang 150001, China

Full list of author information is available at the end of the article
}

with monocytes $[1,3,4]$. Stress or immunosuppression can increase the EIAV replication level in asymptomatic carriers and thus lead to a recurrence of EIA. Because most EIAV-infected equines become asymptomatic carriers due to immune control of the infection, EIAV has become a unique lentivirus model for studies investigating the immune control of lentivirus infection and its pathogenesis. In addition, most asymptomatic EIAV-infected horses demonstrate a significant resistance to infections caused by different pathogenic EIAV strains [1,5]. This finding suggests that the EIAV system can provide a model for studying key immune factors that are involved in resistance to lentiviral infection, which can be used for the research and development of preventive lentivirus vaccines.

EIAV $_{\mathrm{FDDV} 13}$ is an attenuated EIAV vaccine strain that induces immune protection in approximately $80 \%$ of vaccinated animals in laboratory and clinical studies [6,7]. An 
understanding of the mechanism that underlies the induction of immune protection imparted by this attenuated vaccine strain will be useful for elucidating the immune protective mechanism that is responsible for lentivirus infection. Furthermore, the induction of immune protection results from the interaction between viruses and hosts. Therefore, the cellular responses of equine macrophages, the primary target cells of EIAV in vivo, should be evaluated after being infected by EIAV.

In this study, we examined the infection characteristics of a pathogenic EIAV strain EIAV $_{\mathrm{UK} 3}$ on equine macrophages pre-infected by EIAV $\mathrm{FDDV}_{3}$ in vitro. We confirmed that EIAV $V_{\text {FDDV13 }}$ induced a strong resistance to the subsequent EIAV $_{\mathrm{UK} 3}$ infection in equine macrophages. Noticeably, in addition to the previously reported mechanism, i.e. masking viral receptor ELR1 by the SU protein of EIAV $[8,9]$, our results revealed that up-regulation of the soluble EIAV receptor and interferon $\beta$ (IFN $\beta$ ) by activated Tolllike receptor 3 (TLR3) are also largely involved in the resistance to $\mathrm{EIAV}_{\mathrm{UK} 3}$ infection induced by $\mathrm{EIAV}_{\mathrm{FDDV} 13}$.

\section{Materials and methods Cells and viral strains}

eMDM and fetal donkey dermal (FDD) cells were used in this study as target cells for EIAV. The eMDM were prepared from the PBMC of one donor horse. The red blood cells $(\mathrm{RBC})$ of equine animals have a faster sedimentation velocity than the white blood cells (WBC) in natural sedimentation in heparinized whole blood without any other treatment. After at least $30 \mathrm{~min}$ natural sedimentation, RBC will stay in the bottom of the flask, but most WBC including monocytes will stay on the upper layer with the plasma. Thus, the upper plasma layer supernatant including WBC was obtained from freshly collected, heparinized whole horse blood following natural sedimentation at room temperature for $30 \mathrm{~min}$. The blood cells in the supernatant were isolated with centrifugation at $1000 \mathrm{rpm}$. After 2-3 washes with cold phosphate-buffered saline (PBS), the cells were incubated in RPMI 1640 culture medium (Gibco: Invitrogen Corporation, Carlsbad, CA, USA) supplemented with 10\% horse serum (Hyclone, Logan, USA) and 40\% fetal bovine serum (FBS) (Hyclone) at $37{ }^{\circ} \mathrm{C}$ and $5 \% \mathrm{CO}_{2}$. After $24 \mathrm{~h}$ of incubation, non-adherent and loosely adherent cells were removed by washing with cold PBS quickly for three times. The remaining adherent cells were detached with normal saline at $37^{\circ} \mathrm{C}$ and seeded into 96-, 24-, or 6-well microplates (Costar, Corning, USA) for 24 incubation at $1 \times 10^{5}, 1 \times 10^{6}$, and $5 \times 10^{6}$ cells/well, respectively, depending on the experiment. After $48 \mathrm{~h}$ incubation, most adherent cells had differentiated into macrophages (see Additional file 1 to identify the differentiation from monocytes to macrophages by specific immune-staining) and were further used for EIAV infection assays. The FDD cell cultures were prepared and stored in our laboratory. FDD cells were prepared from EIAV negative fetal donkeys and cultured in minimal essential medium ( $\alpha$-MEM, Gibco) containing $2 \mathrm{mM}$ L-glutamine, 10\% heat-inactivated FBS, $100 \mathrm{IU}$ penicillin, and $100 \mu \mathrm{g} / \mathrm{mL}$ streptomycin (Gibco) as previously described [10].

Two EIAV strains were used in this study. EIAV $_{\text {FDDV13, }}$ an attenuated vaccine strain of EIAV, was developed by passaging $\mathrm{EIAV}_{\mathrm{DLV121}}$, a Chinese donkey leukocyte-adapted attenuated strain of EIAV, in FDD cells for 13 generations. A protective test demonstrated that $\mathrm{EIAV}_{\mathrm{FDDV} 13}$ induced protection from disease in approximately $80 \%$ of vaccinated horses [7], and the strain remained stably attenuated in the hosts [11]. $\mathrm{EIAV}_{\mathrm{UK} 3}$, a pathogenic strain of EIAV, is an infectious clone constructed from the backbone of an EIAV $_{\text {wyoming }}$ strain [12]. This infectious clone was kindly provided by Dr R. Montelaro of the Center for Vaccine Research at the University of Pittsburgh. The genomic variation at the nucleotide level between EIAV FDDV13 and EIA$\mathrm{V}_{\mathrm{UK} 3}$ was approximately $25 \%$.

\section{Quantification of EIAV load and detection of viral replication} Real-time quantitative reverse transcription PCR (RTPCR) and reverse transcriptase activity (RT) assays were used to identify the EIAV load. The relative titers of EIAV $_{\mathrm{FDDV} 13}$ and EIAV $\mathrm{UK}_{3}$ were comparable and consistent when measured with these methods. Therefore, a quantitative RT-PCR assay of viral genomic RNA was used to quantify the loads of EIAV $\mathrm{FDDV}_{13}$ and EIAV $\mathrm{UK}_{\mathrm{UK}}$ according to previously described procedures $[6,13]$.

The infectious titer of the two EIAV strains was tested using the median tissue culture infective dose method $\left(\mathrm{TCID}_{50}\right)$. Fifty microliters of viral supernatants that were serially diluted by $10^{-4}, 10^{-5}, 10^{-6}$, and $10^{-7}$ was added to eight wells of 96-well flat-bottom plates; each well contained $5 \times 10^{5}$ FDD cells. After an initial incubation of $2 \mathrm{~h}$, viruses in the culture medium were removed with three washes with serum-free medium. Fresh cell culture medium was then added to the cultures, and the infected cells were incubated continuously. Four days later, EIAV growth was monitored by measuring viral RT activity using a Roche RT detection kit (Roche, Basel, Switzerland). Optical density values two-fold higher than those determined for the negative control were considered to indicate viral replication. The $\mathrm{TCID}_{50}$ value of the virus was determined as described by Reed and Muench [14].

To examine the proliferation profiles of EIAV in eMDM, $1 \times 10^{5}$ cells were infected with $1 \times 10^{3} \mathrm{TCID}_{50}$ of EIAV $_{\text {FDDV13 }}$ (amounted to approximately $1 \times 10^{7}$ viral RNA copies of $\mathrm{EIAV}_{\mathrm{FDDV} 13}$ ) or $1 \times 10^{3} \mathrm{TCID}_{50}$ of $\mathrm{EIAV}_{\mathrm{UK} 3}$ in a 96-well microplate as indicated in the text. The culture medium was exchanged for fresh culture medium after $2 \mathrm{~h}$ of infection. The cells in some wells were used to determine the intracellular viral RNA copies at $3 \mathrm{~h}$ after infection by EIAV. These cells were washed three times with PBS and 
treated with trypsin-EDTA (0.25\% trypsin, 5 mM EDTA) at room temperature for $5 \mathrm{~min}$ to remove adherent virus that had not entered the cells. The other cells that were used to examine the proliferation profiles were further incubated for $2,3,4,5,6$, or 7 days, after which the cell culture supernatants were collected. Triplicate wells were used for each detection time point. Total RNA was extracted from the harvested cells and culture supernatants using Trizol (Invitrogen, Carlsbad, CA, USA) or the QIAamp Viral RNA Mini Kit (Qiagen, Hilden, Germany) and was processed for cDNA synthesis using M-MLV reverse transcript kit (Invitrogen) using 100 ng of RNA template. The cDNA obtained was used for qPCR analysis. The replication kinetics of the viruses was determined in three independent experiments.

\section{Co-infection measured by RNA HIS}

EIAV positive-strand RNA in infected cells was detected with a QuantiGene ViewRNA Plate-based Assay Kit (Panomics, Silicon Valley, USA). Two sets of specific probes that targeted the EIAV genome at nucleotides 2065 to 3210 of EIAV $_{\mathrm{FDDV} 13}$ (GenBank accession \# GS00329) and nucleotides 1,210 to 2356 of EIAV $_{\mathrm{UK} 3}$ (GenBank accession \# AF016316) were designed and provided by Panomics. The divergences between the two targeted regions of these two EIAV strains $\left(\mathrm{EIAV}_{\mathrm{FDDV} 13}\right.$ and EIA$\left.\mathrm{V}_{\mathrm{UK} 3}\right)$ are $23.1 \%$ and $27.6 \%$, respectively. The eMDM were plated in 96-well plates (Costar) and simultaneously infected with these two EIAV strains. At $48 \mathrm{~h}$ after initial EIAV infection, the cells were fixed with $4 \%$ formaldehyde and dehydrated in ethanol. During the detection process, the cells were rehydrated, permeabilized, digested with protease and hybridized with the specific probes as recommended by the manufacturer. Confocal microscopy and image acquisition were performed with a Leica TCS SP5 (Leica, Wetzlar, Germany).

\section{Measurement of mRNA expression by the branched DNA technique and real-time quantitative RT-PCR}

The branched DNA (bDNA) technique was used to measure the expression levels of multiple genes in the cultured cells. The specific oligonucleotide probe sets for the target genes included equine TLR3, TLR7, TLR8, TLR9, IFN 1 , IFN $\beta$, ELR1, and $\beta$-actin, which were used with the QuantiGene 2.0 Reagent Systems designed and provided by the manufacturer (Panomics). Information regarding the probe sets is provided in Additional file 2. The amounts of multiple target mRNA in each sample were simultaneously determined by measuring the wavelengths of colorcoded microspheres and the intensities of the luminescent emission of streptavidin-conjugated R-phycoerythrin using a Luminex 200 (Molecular Devices, Silicon Valley, USA). All data obtained from the Luminex 200 were analyzed using the Luminex IS2.3 program. A total of 100 events per region were collected. For all of the samples analyzed with the bDNA assay, background signals determined in the absence of target mRNA were subtracted from the signals obtained in the presence of target mRNA. The expression levels of the intracellular mRNA were normalized to $\beta$-actin. Changes in gene expression were calculated by the following method: fold changing value $=($ copies of target mRNA/copies of $\beta$ actin mRNA) treated sample/(copies of target mRNA/copies of $\beta$-actin mRNA) untreated control, and were presented as the $\log _{2}$ mean fold changing value in the results. The ratio of copies between target mRNA and $\beta$-actin mRNA for the untreated control was used as the calibrator and assigned a fold-change expression value of 1 . Three independent experiments were performed for each treatment. In addition, the gene expression of the "housekeeping" $\beta$-actin gene used in this study was detected and compared among different eMDM: those infected with EIAV FDDV13 $_{13}$ and EIAV UK3 $_{3}$ or treated with Poly I:C. The eMDM under different treatments were harvested at different internal times and counted. eMDM with the same numbers were used to quantify mRNA copies of $\beta$-actin by Quantitative real-time RT-PCR.

Quantitative real-time RT-PCR using a kit Platinum ${ }^{\odot}$ SYBR $^{\circ}$ Green qPCR SuperMix-UDG (Invitrogen) which utilizes SYBR Green as a detector was performed by using an MxPro 3005p qPCR system (Stratagene, La Jolla, CA, USA) to analyze the expression of ELR-IN, an alternative splicing isoform of the EIAV receptor ELR1 [15], TLR3, and $\beta$-actin. Primers were designed based on the nucleotide sequence of ELR-IN (GenBank accession \# EF190264) to specifically distinguish ELR-IN from ELR1. The sequences of the primers were IN-FW, 5' GGAGAGTCCTTCAGACCTGAGTTCAC3'; IN-RV, 5' CGCTGCACCTAGGAGAGAAGATTGGC3'. The primers for TLR3 mRNA (GenBank accession \# NM_ 001081798.1) were TLR3-FW, 5' GGGCAAGAACTC ACAGGTCAG 3'; TLR3-RV, 5' CAAACCAGGCAAT GCTTTCAC 3'. The primers for $\beta$-actin mRNA were F2, 5' CGACATCCGTAAGGACCTGTA 3'; R2, 5' CA TCTGCTGGAAGGTGGACAA 3'. Total RNA was extracted from the harvested cells using Trizol (Invitrogen) and was processed for CDNA synthesis using an M-MLV reverse transcript kit (Invitrogen,) using $100 \mathrm{ng}$ of RNA template. The cDNA obtained was used for qPCR analysis. qPCR was conducted under the following conditions suggested by the manufacturer of Platinum SYBR Green qPCR SuperMix-UDG kit (Invitrogen): initial preincubation at $50{ }^{\circ} \mathrm{C}$ for $20 \mathrm{~s} ; 95^{\circ} \mathrm{C}$ for $10 \mathrm{~min} ; 40$ cycles of $95{ }^{\circ} \mathrm{C}$ for $30 \mathrm{~s}$ and $60{ }^{\circ} \mathrm{C}$ for $1 \mathrm{~min}$; and one cycle of $95{ }^{\circ} \mathrm{C}$ for $1 \mathrm{~min}, 55^{\circ} \mathrm{C}$ for $30 \mathrm{~s}$ and $95^{\circ} \mathrm{C}$ for $30 \mathrm{~s}$ for signal sampling. Linear regression analysis of the standard curve and the $\beta$-actin values was used to estimate the ELR-IN and TLR3 mRNA level in the samples. 
Enzyme-linked immunosorbent assay for equine IFN- $\alpha / \beta$ Enzyme-linked immunosorbent assays (ELISA) for the analysis of equine IFN $\alpha$ and IFN $\beta$ proteins were performed as described in the protocol provided by the manufacturer (Uscn Life Science, Wuhan, China). The plate was read with a microplate reader VERSAmax (Molecular Devices). The protein expression levels of IFN were measured by ELISA as $\mathrm{pg} / \mathrm{mL}$ calibrated with a set of standards provided by this kit, and the changes in protein expression levels in each sample were calculated using the following formula: fold changing value = the amount of target protein in the treated samples/the amount of target protein in untreated samples, and the mean values of fold change were converted to $\log 2$. The amount of IFN proteins in the untreated control was used as the calibrator and assigned a fold-change expression value of 1 . All reactions were performed in triplicate.

\section{EIAV infection of poly I:C-treated eMDM}

eMDM were cultivated in 96-well plates and treated with either $0.5 \mu \mathrm{g} / \mathrm{mL}$ poly I:C (Sigma-Aldrich, St Louis, USA) or the same volume of PBS as a control. The culture supernatant was removed $12 \mathrm{~h}$ after the treatment, and fresh medium was added. The cells were then infected with $1 \times 10^{3} \mathrm{TCID}_{50}$ of EIAV $\mathrm{UK}_{\text {K } 3}$. After $2 \mathrm{~h}$ of incubation, the culture medium was removed, and the cells were washed three times with PBS before incubation in fresh medium for an additional $72 \mathrm{~h}$. The viral copy numbers in the culture medium of triplicate wells were quantitatively analyzed by qPCR.

\section{RNA interference of TLR3 expression}

To knock down TLR3 expression, a TLR3-specific small interfering RNA (siRNA-TLR3) and a control siRNA (siRNA-C) with scrambled sequences were synthesized by RiboBio, Guangzhou, China. The target sequence was $5^{\prime}$-G GACCTTGGCCTTAATGAA-3', and the product number for siRNA-C was Ncontrol_05815. Primary eMDM were plated in 96-well plates at $1 \times 10^{5} /$ well and transfected with either $50 \mathrm{nM}$ siRNA-TLR3 or $50 \mathrm{nM}$ siRNA-C using the transfection reagent FuGENE HD (Promega, Madison, USA) according to the manufacturer's protocol. The cells were harvested at $48 \mathrm{~h}$ after transfection and evaluated for the efficacy of TLR3 mRNA knockdown.

\section{Statistical analysis}

All experiments in the present study were replicated at least three times unless specifically indicated. The results in the figures are presented as the mean \pm SEM. Significant differences between samples or groups were determined with the student's $t$-test. The statistical analysis was performed using SAS 8.1 software.

\section{Results}

EIAV $_{\text {FDDV13 }}$ induced strong resistance to the infection of EIAV $_{\text {Uк3 }}$ on eMDM

To examine the ability of EIAV $\mathrm{FDDV}_{33}$ to interfere with the infection of EIAV $_{\mathrm{UK} 3}$, a pathogenic EIAV strain, EIAV $_{\mathrm{FDDV} 13}$ and EIAV $\mathrm{UK}_{\mathrm{UK} 3}$ viruses at the same infectious titer were first used to infect equal numbers of eMDM The infection and replication patterns of the two strains were analyzed with qRT-PCR. The intracellular viral copy numbers determined in early-phase infection (3 hours post-infection (hpi)) indicate that the number of viruses that entered the cells was similar for the two strains (Figure 1A). The co-presence of both EIAV FDDV13 and EIAV UK3 $_{3}$ in infected cells was examined by ViewRNA in situ hybridization using probes labeled with different fluorescent dyes. The images of EIAV in infected cells presented in Figure $1 \mathrm{~B}$ clearly demonstrate that these two viral strains co-infected and replicated in common macrophages. Furthermore, the replication kinetics of EIAV $\mathrm{FDDV}_{33}$ and $\mathrm{EIAV}_{\mathrm{UK} 3}$ in the cell culture medium during the seven-day post-infection period was examined using inocula normalized by either $\mathrm{TCID}_{50}$ or RNA copy numbers. Besides a slight decreased viral load of EIAV $_{\mathrm{FDDV} 13}$ on 4 days post infection (dpi), the two EIAV strains grew equally well in cultivated eMDM with similar replication kinetics regardless whether initially normalized by infectivity or viral particles (Figure $1 C$ ). In addition, the difference in the ratio of RNA copy number/infectious titer in the viral stocks, which represents the difference in infectivity of EIAV in the target cells [16], was measured. The measured ratios for EIAV $\mathrm{FDDV}_{33}$ and EIAV $\mathrm{UK}_{3}$ were $33133.73 \pm 2204.662$ and $29245.28 \pm 2037.972$, respectively, with no significant difference $(P=0.14)$. These results indicate that the two EIAV strains used in this study replicated in eMDM with similar kinetics and similar cell-cell spreading efficacies.

Afterwards, the restriction of a subsequent infection with EIAV $\mathrm{UK}_{\mathrm{UK}}$ by pre-infection with $\mathrm{EIAV}_{\mathrm{FDDV} 13}$ or a subsequent infection with EIAV $\mathrm{FDDV13}_{\text {13 }}$ by pre-infection with EIAV $_{\mathrm{UK} 3}$ was investigated. The viral RNA copy numbers of EIAV ${ }_{\mathrm{UK} 3}$ or EIAV $\mathrm{FDDV}_{33}$ in eMDM pre-infected with EIAV $_{\mathrm{FDDV} 13}$ for $6,12,24,36$ and $48 \mathrm{~h}$ were measured and compared with the EIAV RNA copy numbers in control groups (cells not treated with pre-infection of EIAV). As shown in Figure 1D, the RNA copy numbers of EIAV ${ }_{\mathrm{UK} 3}$ were markedly reduced by $92.68 \pm 3.35 \%$ by prior infection with EIAV $_{\text {FDDV13 }}$ for $6 \mathrm{~h}$ compared with the control group. The restriction effect increased by approximately 5 -fold with prolonged pre-infection time until $24 \mathrm{~h}$, at which point the reduction in RNA copy number was $98.71 \pm 0.48 \%$. In contrast, the resistance induced by EIA$\mathrm{V}_{\mathrm{UK} 3}$ to subsequent infection by $\mathrm{EIAV}_{\mathrm{FDDV} 13}$ was much weaker. The restriction induced by $\mathrm{EIAV}_{\mathrm{UK} 3}$ was approximately $85 \%$ throughout the detection period and was 10 - 
A

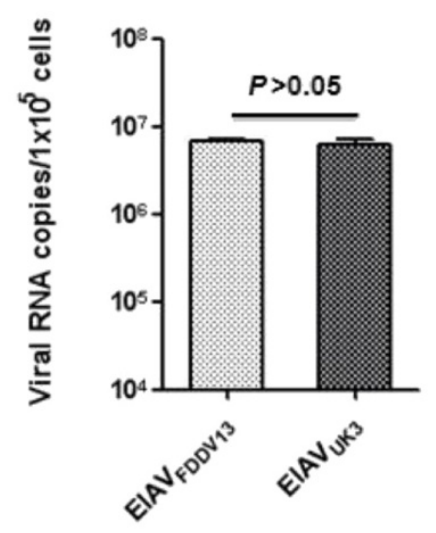

\section{C}

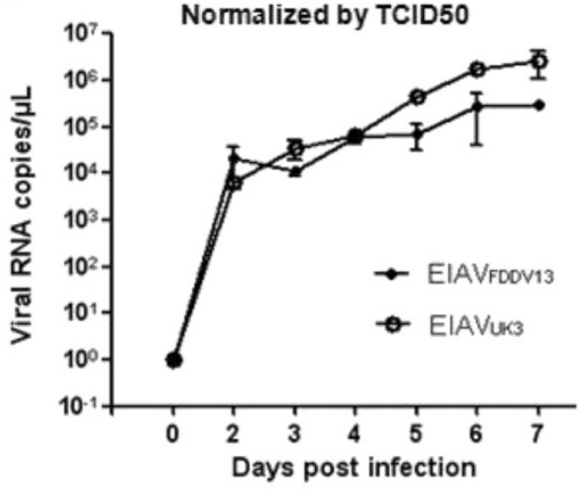

D

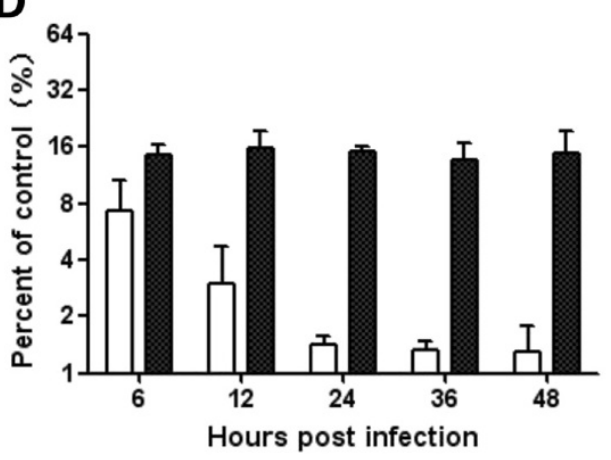

B
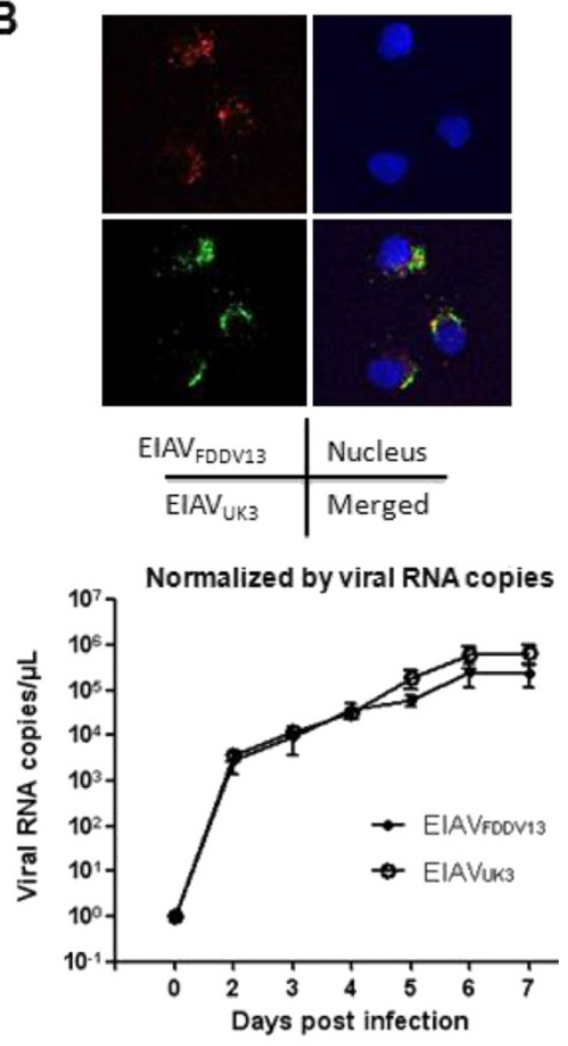

EIAVUK3

EIAVFDDV13

Figure 1 EIAV $_{\text {FDDV13 }}$ induced strong resistance to subsequent infection of EIAV $\mathrm{UK}_{33}$ in eMDM. (A) Comparison of intracellular viral levels in the early phase of infection. The same infectious dose $\left(1 \times 10^{3} \mathrm{TCID}_{50} /\right.$ well $)$ of the attenuated EIAV strain EIAV FDDV13 and the pathogenic strain EIAV $\mathrm{UK}_{3}$ was used to infect eMDM in 96-well microplates. At $3 \mathrm{hpi}$, the copy numbers of intracellular EIAV RNA were measured with qPCR.

(B) Co-infection of eMDM with EIAV FDDV13 and EIAV $V_{U K 3}$. Cultivated eMDM were simultaneously infected with equivalent $\mathrm{TCID}_{50} \mathrm{Of} \mathrm{EIAV}_{\mathrm{FDDV} 13}$ and EIAV $_{U K 3}$. Intracellular viruses were detected with ViewRNA in situ hybridization at $48 \mathrm{hpi}$ and are indicated as fluorescently labeled granules (red for EIAV $\mathrm{FDDV}_{13}$ and green for EIAV $\mathrm{VKK}_{3}$ ). (C) Comparison of the replication kinetics of ElAV FDDV13 and EIAV $V_{U K 3}$ in eMDM. Stocks of these two viruses with an equal TCID 50 or equal RNA copy numbers were used to infect eMDM as indicated. Viruses in the culture medium were quantified as viral

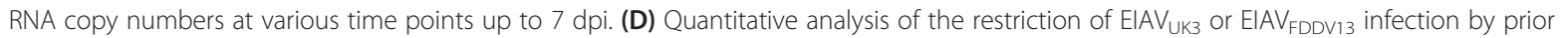
EIAV FDDV13 $_{\text {Or EIAV }}$ iK3 infection. Cultivated eMDM were pre-infected by $1 \times 10^{3} \mathrm{TCID}_{50}$ of EIAV FDDV13 or EIAV $\mathrm{VKK}_{3}$ in 96 -well plates. The culture medium was changed after $2 \mathrm{~h}$ of infection. The cells were washed three times with PBS at 6, 12, 24, 36 and 48 hpi and were infected with equivalent infectious amounts of EIAV $\mathrm{UK}_{3}$ Or EIAV FDDV13 diluted in the culture medium. After another $48 \mathrm{~h}$, the culture supernatant was collected and the viral loads of the subsequently infected virus in the medium were measured as the copy numbers of ElAV RNA. The Y-axis of the graph represents the ratio of viral RNA copies to the number of viral RNA copies in cells without pre-infection with EIAV.

20 -fold lower than that induced by EIAV $\mathrm{FDDV} 13_{3}$ after $24 \mathrm{~h}$ of pre-infection. Meanwhile, there was no significant difference in apoptosis of eMDM induced by the infection of these two EIAV strains (see Additional file 3), which ruled out the possible effect of cell degradation on the aforementioned difference in viral RNA replication. These 
results demonstrate that the initial infection of EIAV $\mathrm{FDDV}_{3}$ in eMDM induced a strong resistance to the subsequent infection of EIAV $\mathrm{UK}_{\mathrm{UK}}$.

\section{Infection of eMDM with EIAV $\mathrm{FDDV} 13_{3}$ and EIAV $\mathrm{UK3}$ differentially influenced the expression of ELR1 and soluble ELR1 (sELR1)}

The EIAV receptor ELR1 has been shown to play an important role in induction of superinfection resistance (SIR) [9]. To investigate the role of ELR1 in the infection resistance induced in eMDM by EIAV $_{\mathrm{FDDV} 13}$, a quantitative analysis of ELR1 mRNA levels in eMDM up to 36 hpi with EIAV $\mathrm{FDDV13}_{\text {13 }}$ was performed. As a provirusderived pathogenic strain, the inductive activity of EIA$\mathrm{V}_{\mathrm{UK} 3}$ was also investigated to compare it with that of

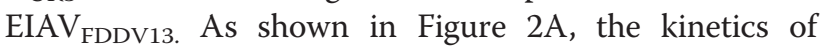
ELR1 mRNA expression was similar in eMDM infected with the two viruses: ELR1 expression was first downregulated and then up-regulated. However, both downregulation and up-regulation occurred over a limited range, and down-regulation only occurred within $6 \mathrm{hpi}$, suggesting a limited involvement of ELR1 regulation in EIAV-induced infection resistance. Meanwhile, $\beta$-actin expression in eMDM was not influenced after being infected with EIAV ${ }_{\text {FDDV13 }}$ and EIAV $_{\mathrm{UK} 3}$ (see the result in Additional file 4). It ensured the validity of the data for gene expression dynamics obtained in this study.

We recently identified an alternative splicing variant of ELR1 transcripts that retained a fragment of intron 6. This sliced transcript, termed as ELR-IN (GenBank accession \# EF190264), accounts for a large proportion of ELR1 transcript variants (approximately 50\% of the ELR1 transcript) and creates an isoform with four different amino acid residues and then a premature stop codon 14 residues upstream of the predicted membrane spanning domain. The truncated ELR1 protein is predicted and confirmed as a soluble form of ELR1. A separate study revealed that sELR1 appeared to inhibit EIAV infection in cultivated host cells [15]. Therefore, the regulation of ELR-IN expression by EIAV infection was tested. The levels of sELR1 mRNA in eMDM infected with $\mathrm{EIAV}_{\mathrm{FDDV} 13}$ were significantly higher than in EIAV $\mathrm{UK}_{\mathrm{UK}}$-infected cells and uninfected control cells within 12-24 h after infection, differently than that was observed for transmembrane ELR1 (Figure 2B). This result suggests that the up-regulation of sELR1 expression in eMDM after infection with $\mathrm{EIAV}_{\mathrm{FDDV} 13}$ may contribute to induction of infection resistance by this EIAV strain.

The expression levels of viral nucleic acid-recognizing TLR and type I interferons were differentially regulated by EIAV $_{\text {FDDV13 }}$ and EIAV UKз $_{3}$ infection in eMDM

Because macrophages, the primary target cells of EIAV in vivo, are important in immune responses and are essential for the effects of TLR activation on the innate antivirus mechanisms of immunocytes, the activation of TLR3, TLR7, TLR8 and TLR9, which are activated by single-stranded or double-stranded foreign RNA or foreign DNA, was analyzed. As shown in Figure 3A, EIAV $_{\text {FDDV13 }}$ significantly up-regulated TLR3 mRNA expression, with a peak (8- to 10 -fold) at 24 hpi. However, EIAV $_{\mathrm{UK} 3}$ had no effect on TLR3 mRNA levels. With regards to TLR7 and TLR8 expression, EIAV UK3 $_{\text {up- }}$ regulated TLR expression approximately 0.5 - to 1.5 -fold at 12 to 24 hpi, but EIAV FDDV13 $_{3}$ did not exhibit such an effect. No significant difference in TLR9 expression was observed in eMDM infected with EIAV FDDV13 $_{13}$ and EIAV $\mathrm{UK}_{\mathrm{UK}}$; both strains moderately up-regulated TLR9 expression (see Additional file 5).
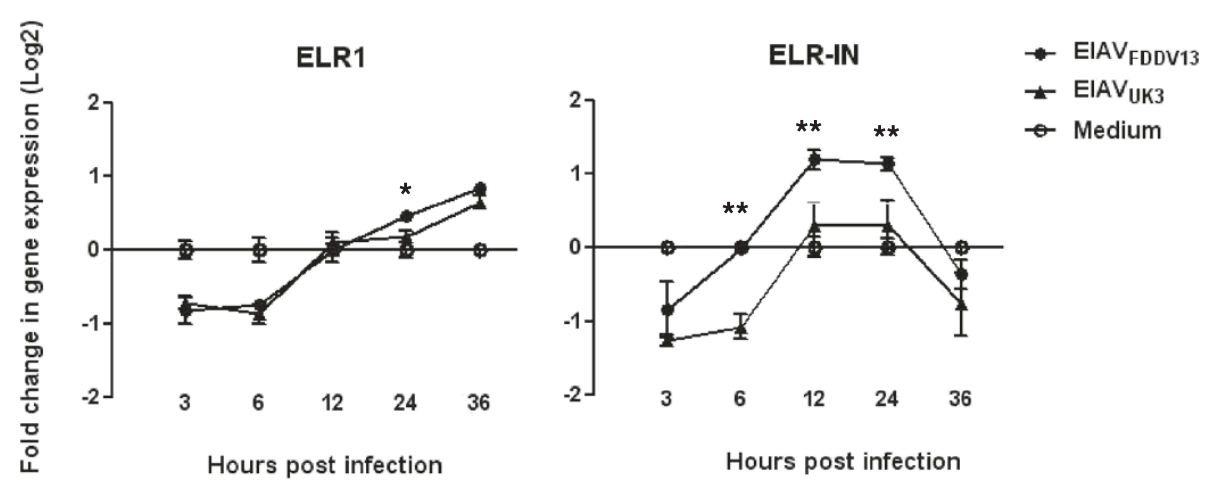

Figure 2 Regulation of membrane-bound and soluble EIAV receptor expression in eMDM by EIAV FDDV13 $_{\text {and EIAV }}$ UK3. (A) Regulation of membrane-bound EIAV receptor ELR1 expression. Total RNA was extracted from eMDM that were infected with equal infectious titers of either EIAV $_{\text {FDDV13 }}$ or EIAV $\mathrm{UK}_{3}$ for various times. ELR1 mRNA was quantified with a branched DNA (bDNA) assay. (B) Regulation of soluble EIAV receptor expression. ELR-IN is a transcriptional variant of ELR1 that encodes a soluble form of the receptor (sELR1). The expression levels of ELR-IN in eMDM infected with either EIAV FDDV13 or EIAV $\mathrm{UK}_{3}$ for various times were quantified with real-time $\mathrm{GPCR}$. The values of $Y$ axis were treated by Log2. ${ }^{*} P<0.05,{ }^{*} P<0.01$. 


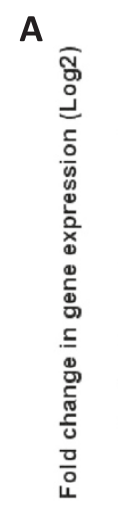

B

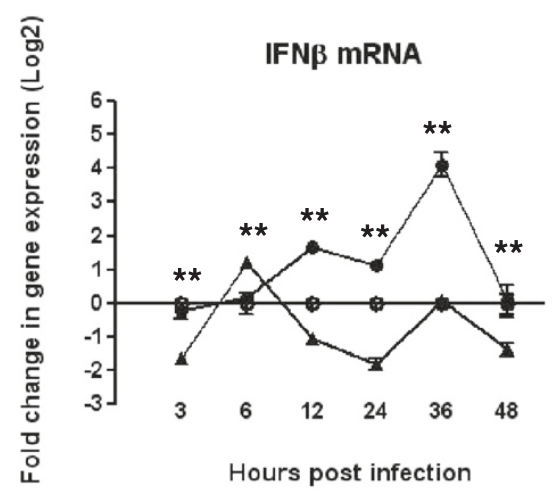

$$
\begin{aligned}
& \text { - EIAV FDDV13 } \\
& \text { EIAV } \text { EIK } 3 \\
& \text { - Medium }
\end{aligned}
$$

C

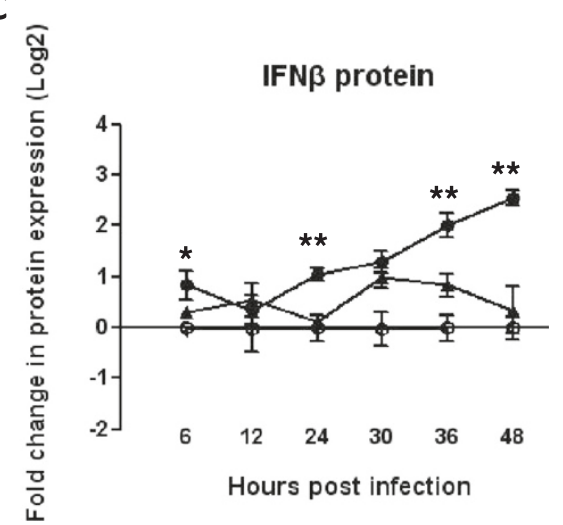

Figure 3 Regulation of TLR3 and IFN $\beta$ expression in eMDM by EIAV $\mathrm{FDDV}_{13}$ and EIAV $_{\mathrm{UK} 3}$. EMDM infected with equal infectious titers of either EIAV $_{\text {FDDV13 }}$ or EIAV $V_{U K 3}$ for various times were selected. Some cells were treated with Trizol, and the total RNA was extracted to quantify TLR3 (A) and IFN $\beta$ (B) mRNA expression with the bDNA assay. The remaining cells were lysed with RIPA cell lysis buffer, and the protein levels of IFN $\beta$ in the eMDM lysates were measured with an ELISA kit (C). The values of $Y$ axis were treated by Log2. ${ }^{* *} P<0.01$.

Studies have shown that type I interferons are associated with intracellular TLR activation and that they are part of the downstream products of TLR signaling pathways [17-19]. Given the obvious up-regulation of TLR3 mRNA expression by EIAV $\mathrm{FDDV}_{13}$ infection and the antiviral activity of type I interferons, changes in the expression of IFN $\beta$ and IFN $\alpha$ in eMDM after infection with EIAV $_{\mathrm{FDDV} 13}$ and EIAV $\mathrm{UK}_{\mathrm{U} 3}$ were evaluated. As shown in Figure $3 B$, there were significant differences in IFN $\beta$ expression in eMDM infected with the two strains. At $24 \mathrm{~h}$ after the infection of eMDM with EIAV $\mathrm{FDDV}_{13}$, IFN $\beta$ expression was up-regulated by 10 - to 20 -fold at the mRNA level and 4- to 6-fold at the protein level compared with the mock-treated control; the timing of this up-regulation was correlated with the temporal upregulation of TLR3 expression in eMDM infected with EIAV $_{\mathrm{FDDV13}}$. In contrast, IFN $\beta$ mRNA and protein expression in eMDM infected with $\mathrm{EIAV}_{\mathrm{UK} 3}$ did not differ significantly from those in the mock-treated control. Although EIAV $_{\mathrm{UK} 3}$ infection up-regulated IFN $\alpha$ expression (approximate 3 folds in protein level), infection with EIAV $_{\text {FDDV13 }}$ basically did not (Additional file 6). Based on the antiviral effect of IFN $\beta$, it is likely that the up-regulation of IFN $\beta$ expression is positively correlated with the strong infection resistance induced by EIAV $_{\text {FDDV13. }}$.

\section{TLR3 activation in eMDM induced by poly I:C resulted in increased sELR1 and IFN $\beta$ mRNA expression}

Considering the correlation between strong induction of infection resistance and elevated TLR3 and IFN $\beta$ expression induced by attenuated $\mathrm{EIAV}_{\mathrm{FDDV} 13}$ as well as the existence of a signaling pathway linking TLR3 activation with IFN $\beta$ expression, the effect of TLR3 activation on infection resistance induced by $\mathrm{EIAV}_{\mathrm{FDDV} 13}$ was mimicked by treating eMDM with poly I:C, a TLR3 ligand. Treatment with poly I:C at $0.5 \mu \mathrm{g} / \mathrm{mL}$ up-regulated TLR3 mRNA expression to similar levels as those observed in eMDM infected with EIAV FDDV13 (Figure 4A). In addition, replication of the pathogenic EIAV strain EIAV $_{\mathrm{UK} 3}$ in poly I:C-treated cells declined by approximately $90 \%$ compared with untreated cells (Figure 4B). By the way, $\beta$-actin expression was at a similar level in eMDM after being treated with poly I:C or being infected with the two EIAV strains used in this study (see Additional file 4). This could also ensure the validity of the data for gene expression dynamics obtained in this experiment. 


\section{A}

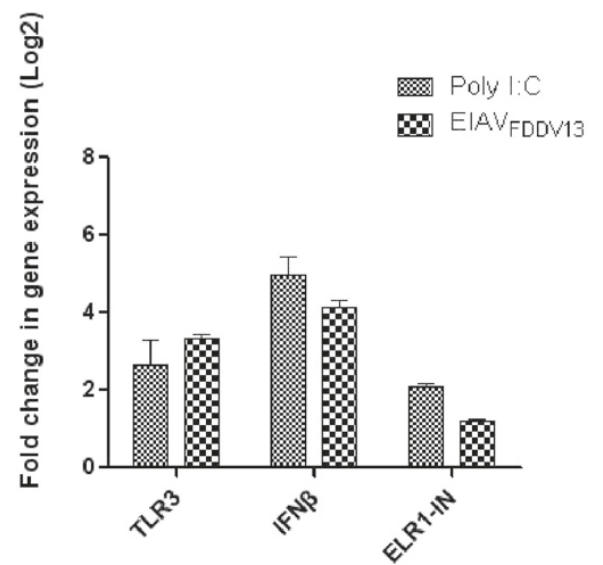

B

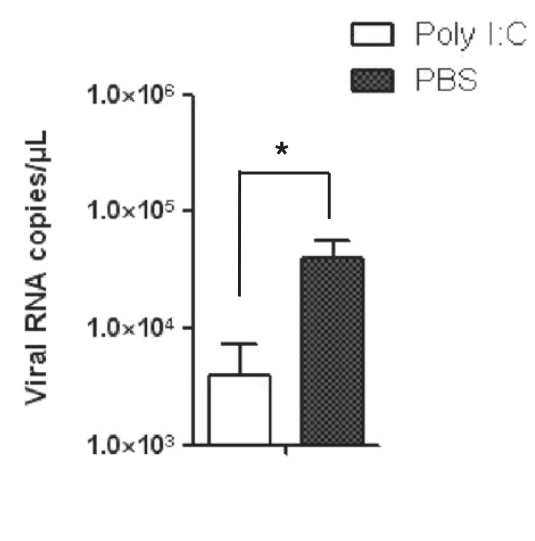

Figure 4 Effects of poly I:C on TLR3, type I interferons and sELR1 expression and EIAV replication. (A) Effects of poly I:C on TLR3, IFN 3 and sELR1 expression. eMDM were treated with poly l:C $(0.5 \mu \mathrm{g} / \mathrm{mL})$ for $12 \mathrm{~h}$. The expression levels of specific mRNA in the cells were analyzed using the bDNA assay. The values of $Y$ axis were treated by Log2. (B) Effects of poly I:C on EIAV $V_{U k 3}$ replication. eMDM were treated with either $0.5 \mu \mathrm{g} / \mathrm{mL}$ poly I:C or the same volume of PBS as a control for $12 \mathrm{~h}$; the cells were then infected with ElAV UK3. Viral RNA copy numbers in the culture medium were measured with real-time $\mathrm{qPCR}$ at 72 hpi. ${ }^{*} P<0.05$.

Intriguingly, following the specific activation of TLR3 by poly I:C in eMDM, the mRNA expression levels of both IFN $\beta$ and sELR1 were up-regulated. The up-regulation of IFN $\beta$ was similar to that observed in EIAV $\mathrm{FDDV}_{\mathrm{F} 3}$-infected eMDM (Figure 4A). Moreover, expressions of IFN $\alpha$ and TLR7-9, which show lower intensity induced by attenuated EIAV FDDV13 $_{\text {than }}$ that induced by the virulent EIA$\mathrm{V}_{\mathrm{UK} 3}$ or show a limited difference between these two EIAV strains, were also not up-regulated after poly I:C treatment (data not shown). These results indicate that enhanced IFN $\beta$ and sELR1 expression can be induced by TLR3 activation, which in turn promotes resistance of the target cells to EIAV infection.

\section{TLR3 activation in eMDM played an important role in} induction of infection resistance to EIAV $_{\mathrm{UK} 3}$

To confirm that up-regulated TLR3 expression plays a crucial role in the induction of infection resistance in EIAV $_{\text {FDDV13-infected }}$ eMDM, TLR3 expression in eMDM was knocked down with siRNA. As shown in Figure 5A, TLR3 transcription was reduced by approximately $65 \%$ in eMDM transfected with horse TLR3 siRNA (siRNA-TLR3) compared with cells transfected with scrambled RNA control siRNA-C. When the siRNA-TLR3-transfected cells were treated with $0.5 \mu \mathrm{g} / \mathrm{mL}$ poly I:C for $12 \mathrm{~h}$, only a slight up-regulation of TLR3 mRNA expression (0.5-fold) was observed, whereas an approximately 8.0-fold increase in TLR3 mRNA expression was detected in siRNAC-transfected cells (Figure $5 \mathrm{~B}$ ). These results indicate that TLR3 expression was substantially suppressed by its specific siRNA. The effect of EIAV FDDV13 on TLR3, sELR1 and IFN $\beta$ expression was evaluated after TLR3 knockdown. As shown in Figure 5C, compared with the effect of EIAV $\mathrm{FDDV13}_{13}$ on eMDM that were not treated with siRNA, the up-regulation of these three factors was greatly diminished in cells transfected with specific siRNA-TLR3.

Furthermore, to determine whether the inhibitory effects of poly I:C on EIAV replication and infection resistance induced by EIAV $_{\mathrm{FDDV} 13}$ infection in eMDM were reduced after TRL3 knockdown, the viral copy numbers of EIAV $\mathrm{UK}_{\mathrm{UK}}$ in siRNA-TLR3-transfected, siRNA-C-transfected and untransfected eMDM were analyzed after stimulation with poly $\mathrm{I}: \mathrm{C}$, and the induction of infection resistance by EIAV $\mathrm{FDDV}_{\text {13 }}$ was evaluated in siRNA-TLR3-transfected eMDM. As shown in Figure 6A, the TLR3 ligand poly I:C induced an approximately $90 \%$ reduction of the growth of $\mathrm{EIAV}_{\mathrm{UK} 3}$ in equine macrophages, but failed to effectively inhibit the viral replication in the cells that had been transfected with siRNA-TLR3. More importantly, TLR3 knockdown reversed the inhibition induced by $E_{\text {IAV }}$ FDV13 to the level of $6 \mathrm{~h}$ of pre-infection (Figure 6B).

\section{Discussion}

In this study, we found that in equine macrophages, EIAV $_{\text {FDDV13 }}$ infection could induce strong resistance to subsequent infection of the heterologous virulent EIAV strain EIAV $_{\text {UK3 }}$. Furthermore, we observed that some cellular factors involved in the activation of innate immunity by EIAV $_{\text {FDDV13, which occurred primarily }}$ through TLR3 activation, were important contributors to the development of infection resistance. Such host cell responses could disturb either the entrance or replication of the virus, which results in the decline of viral RNA copies in target cells. As observed in this 


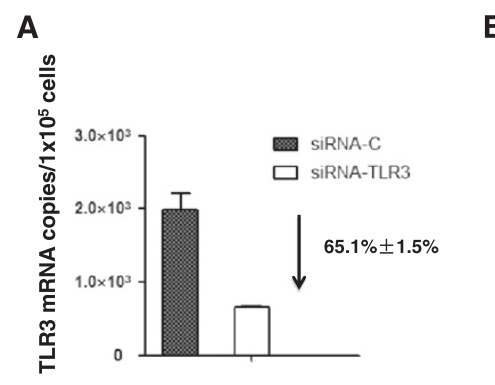

C

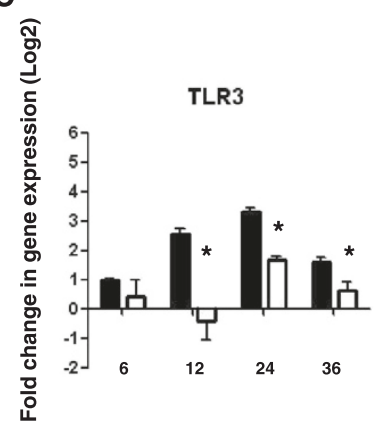

B

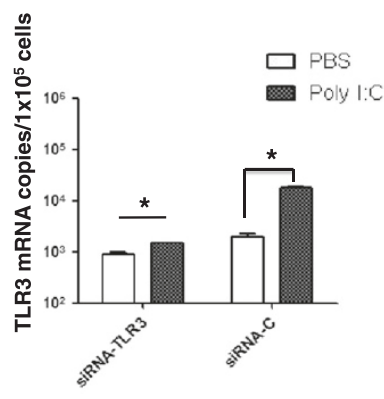

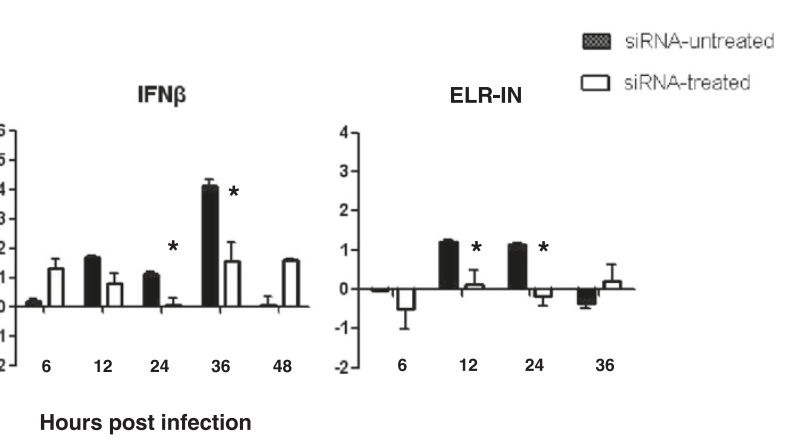

Figure 5 Effects of TLR3 mRNA knockdown on sELR1 and INF $\beta$ expression in eMDM. (A) Knockdown of TLR3 expression in eMDM with siRNA. At $48 \mathrm{~h}$ after transfection with siRNA targeting equine TLR3 (siRNA-TLR3), the expression level of TLR3 mRNA was quantified with real-time qPCR. siRNA with a scrambled sequence (siRNA-C) was used as the control. (B) The induction of TLR3 expression by poly I:C in siRNA-TLR3transfected eMDM. The cells were transfected with siRNA-TLR3 or siRNA-C. TLR3 mRNA was measured with real-time qPCR $12 \mathrm{~h}$ after stimulation with $0.5 \mu \mathrm{g} / \mathrm{mL}$ poly I:C. (C) Kinetics of TLR3, sELR1 and INF $\beta$ mRNA expression induced by EIAV FDDV13 in eMDM transfected with siRNA-TLR3. Cells were transfected with siRNA-TLR3 or siRNA-C. After $48 \mathrm{~h}$ of incubation, EIAV FDDV13 was added to the cells, and total RNA was extracted at different times after infection. The mRNA copies were specifically amplified and quantified with bDNA (for TLR3 and INF $\beta$ ) and qPCR (for sELR1). The values of $Y$ axis were treated by Log2. ${ }^{*} P<0.05$.
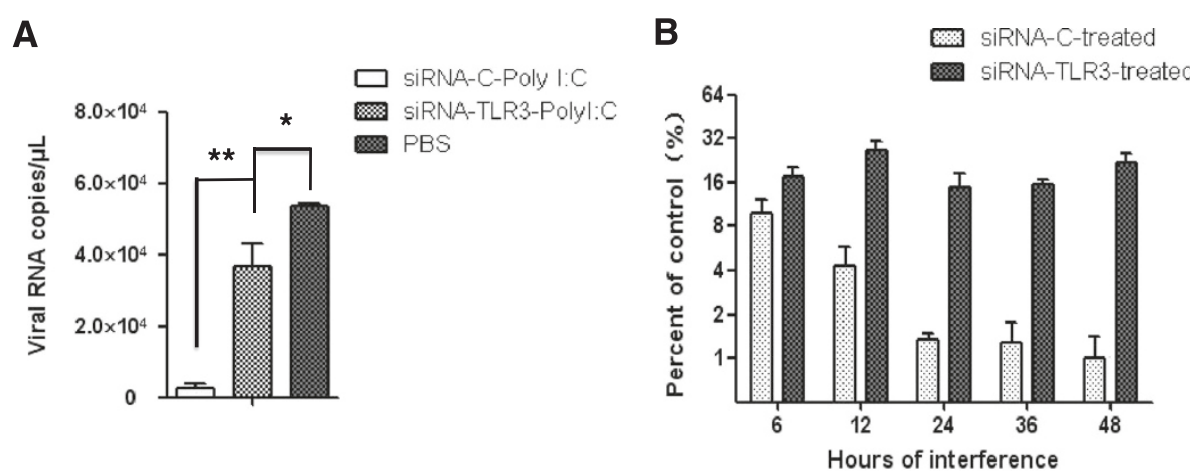

Figure 6 EIAV replication and induction of infection resistance in eMDM after TLR3 mRNA knockdown. (A) The inhibitory effect of poly l: $\mathrm{C}$ on EIAV $\mathrm{VKK}_{3}$ replication in eMDM transfected with specific siRNA-TLR3 or control siRNA-C. After transfection with siRNA for $48 \mathrm{~h}$, the cells were stimulated with $0.5 \mu \mathrm{g} / \mathrm{mL}$ poly l:C for $12 \mathrm{~h}$ before infection with EIAV $V_{U K 3}$. Viral RNA copies were measured with gPCR at 72 hpi. (B) The effect of TLR3 mRNA knockdown on the resistance to subsequent viral infection induced by EIAV FDDV13. eMDM transfected with TLR3-specific or control siRNA were first infected with EIAV FDDV13. The cells were subsequently infected with EIAV $V_{U K 3}$ at different times; at $72 \mathrm{~h}$ later, the viral RNA copy numbers of EIAV $V_{U K 3}$ in the culture medium were measured with $\mathrm{QPCR}$ and compared with the EIAV $\mathrm{UKK}_{3}$ RNA copy numbers in eMDM that were not initially infected with ElAV FDDV13. ${ }^{*} P<0.05,{ }^{* *} P<0.01$. 
study, the viral RNA copies of $\mathrm{EIAV}_{\mathrm{UK}}$ in the culture supernatant of macrophages preinfected with $\mathrm{EIAV}_{\mathrm{FDDV} 13}$ were noticeably lower than that in the un-preinfected controls.

The phenomenon that a virally infected cell becomes resistant to subsequent infection by the same or similar viruses is referred to as superinfection resistance (SIR) [20]. In this study, Figure $1 \mathrm{~A}$ shows that at least 10 copies of viral RNA were detected per cell $3 \mathrm{hpi}$. This level of detection suggests that every target cell was infected by EIAV prior to the second infection of EIAV $\mathrm{UK}_{\mathrm{UK}}$. Therefore, SIR is one of the possible mechanisms that takes part in the development of resistance to subsequent viral reinfection. The primary mechanism underlying SIR induction by HIV-1 is down-regulation of the expression of the principle HIV-1 receptor CD4 on the cell surface [20,21]. In the present study, only limited up- or down-regulation on the mRNA level of EIAV receptor ELR1 was detected in eMDM infected with either EIAV FDDV13 $_{3}$ or EIAV UK3. $_{3}$ This observation is consistent with previous reports that the amount of membrane-bound ELR1 was not reduced by EIAV infection [8,9]. In addition, these two EIAV strains acted similarly on ELR1 expression but induced TLR3 expression differently, which implicates that ELR1 does not play an essential role in the resistance to subsequent infection inducted by $\mathrm{EIAV}_{\mathrm{FDDV} 13}$. In contrast to intact membrane-bound ELR1, a 2- to 3-fold difference in the expression of sELR1, the soluble form of ELR1, was detected after infection of eMDM with $\mathrm{EIAV}_{\mathrm{FDDV} 13}$, but not $\mathrm{EIAV}_{\mathrm{UK} 3}$. Because soluble viral receptors generally exert inhibitory effects on viral infection [22-24] and sELR1 mRNA accounts for as much as $50 \%$ of the total ELR1 mRNA present (unpublished data), the changes in sELR1 expression observed after viral infection in this study are likely to be involved in the resistance induced by EIAV. Our results demonstrate that poly I:C stimulated sELR1 expression by specifically activating TLR3 and that sELR1 expression was not up-regulated by EIAV $_{\text {FDDV13 }}$ infection of eMDM after the knockdown of TLR3 mRNA. These data support the hypothesis that TLR3 pathway activation mediates the up-regulated expression of the soluble ELR1 receptor after EIAV infection. However, one should be cautious in evaluating the role of sELR1 in SIR induced by EIAV FDDV13 $_{\text {because of the observed }}$ modest up-regulation of sELR1 mRNA expression and the absence of confirmation at the protein level, which was precluded by the low native expression of sELR1 in eMDM and the lack of a specific antibody that differentiates sELR1 from the prototype ELR1. Beside this, the linkage between TLR3 activation and sELR1 expression is not clear.

In addition to the up-regulation of soluble viral receptors, the enhanced expression of innate immunity-related factors is another mechanism that restrains viral replication and protects cells from subsequent infection. In the present study, we focused on TLR3 and IFN $\beta$. Our results show EIAV $V_{\mathrm{FDDV} 13}$ strongly stimulated TLR3, whereas $\mathrm{EIAV}_{\mathrm{UK} 3}$ did not. TLR3 activation in macrophages has been shown to prevent HIV-1 infection [25], suggesting that the activation of the TLR3 signaling pathway might help macrophages to resist subsequent infection with similar viruses. In this study, stimulating TLR3 expression by poly I:C effectively prevented EIAV infection of the target cells, and TLR3 knockdown with siRNA largely reduced the antiviral effect of poly I:C. Although other pattern recognition receptors (PRR), such as retinoic acid-inducible gene protein I (RIG-I) and melanoma differentiation-associated protein 5 (MDA-5), belong to the RIG-I-like receptor (RLR) family and might also be involved in the innate immune response against EIAV infection, our results indicate that enhancing TLR3 expression alone effectively improved the ability of macrophages to resist to $\mathrm{EIAV}_{\mathrm{UK} 3}$ infection. On the contrary, our results also show that the resistance to subsequent infected EIA$\mathrm{V}_{\mathrm{UK} 3}$ induced by a TLR3 ligand, poly I:C, was noticeably lower than that induced by EIAV $\mathrm{FDDV} 13_{3}(90 \%$ vs $98 \%$ of inhibition), and the knockdown of TLR3 expression by siRNA only reversed $10-20 \%$ resistance to the subsequently infected virus. Even though the incomplete interference of TLR3 expression (about 65\%) partially counts for the incomplete reverse of the EIAV $\mathrm{FDDV}_{13}$-induced SIR, other mechanisms may also be involved in, such as interfering viral entrance by the binding of EIAV gp90 surface protein to the membrane-bound receptor ELR1 $[8,9]$.

Following TLR3 activation by EIAV FDDV13 $_{13}$ IFN $\beta$ production in eMDM also significantly increased, which was consistent with IFN $\beta$ as a major downstream product of this PRR $[26,27]$. Considering the important role of IFN $\beta$ in innate anti-virus function, the significantly up-regulated IFN $\beta$ expression observed in eMDM infected with $\mathrm{EIAV}_{\mathrm{FDDV} 13}$ is considered a key contributor in the infection resistance induced by this virus. In addition to their role in antiviral function, TLR3 and IFN $\beta$ also play important roles in specific adaptive immune responses. In addition to their role in antiviral function, TLR3 and IFN $\beta$ also play important roles in specific adaptive immune responses. These include the promotion of $\mathrm{T}$ cell-dependent and -independent antibody responses in follicular B cells $[28,29]$, the promotion of germinal center formation, the production of neutralizing antibodies [30] and the stimulation of the development of lymph node-resident $\mathrm{T}$ follicular helper cells [31]. These activated immunocytes are critical for the germinal center reaction and humoral immunity response [32]. Therefore, the enhanced upregulation of TLR3 and IFN $\beta$ expression induced by EIAV $_{\text {FDDV13 }}$ likely contributes to the development of specific immunity against EIAV that is elicited in vivo through the inoculation with the attenuated strain. 
Although the same amounts of initial viral titers were added, which were normalized by both $\mathrm{TCID}_{50}$ and viral RNA copy number, and these two viruses had similar replication kinetics and infectivity, EIAV $\mathrm{FDDV}_{13}$ and $\mathrm{EIAV}_{\mathrm{UK} 3}$ induced significantly different TLR3, sELR1 and IFN $\beta$ expression in eMDM. Our data indicate that besides the previous reported mechanism of competitive receptor binding by the viral surface protein, TLR3 pathway activation plays a vital role in the infection resistance induced by EIAV $_{\mathrm{FDDV} 13}$ infection in macrophages in vitro. Therefore, these two viral strains should stimulate the dsRNArecognizing TLR3 with different efficacies. Because the sequence variation in the genomes of EIAV $\mathrm{FDDV}_{33}$ and EIA$\mathrm{V}_{\mathrm{UK} 3}$ is approximately $25 \%[33,34]$, the dsRNA structures formed within the single-strained RNA viral genomes are considered different. In addition, EIAV $\mathrm{FDDV}_{\mathrm{F} 3}$ consists of quasispecies with an average genomic diversity of approximately $3 \%$ while $\mathrm{EIAV}_{\mathrm{UK} 3}$ is derived from a proviral clone $[6,12]$. These differences may influence the binding affinities of PAMP (dsRNA) for TLR3 in these two EIAV strains, and appear to account for the differences in PRR activation and the expression of TLR3-associated cytokines. Besides the aforementioned speculation, another aspect under consideration is that the virulent $\mathrm{EIAV}_{\mathrm{UK} 3}$ may have one or more mechanisms to block or dampen the early innate immune response. Exploration of EIAV-specific mechanisms that are responsible for the suppression of innate immunity by virulent strains should be highly informative. Consequently, the results of this study provide insights that will facilitate a better understanding of the interaction between host cells and EIAV, as well as other lentiviruses.

Our data demonstrate that sELR1 and IFN $\beta$ are upregulated when TLR3 is activated and those cells in which TLR3 is activated show enhanced resistance to EIAV $_{\mathrm{UK} 3}$ infection. Silencing TLR3 expression with siRNA significantly reduces this inhibitory effect. More importantly, infection resistance induced by EIAV $\mathrm{FDDV}_{13}$ is significantly reversed after TLR3 silencing. Based on the significant difference in TLR3 expression in eMDM stimulated with EIAV $_{\text {FDDV13 }}$ and $\mathrm{EIAV}_{\mathrm{UK} 3}$, we hypothesize that TLR3 pathway activation plays an important role in the induction of infection resistance by EIAV $_{\mathrm{FDDV} 13}$ infection in macrophages in vitro.

\section{Additional files}

Additional file 1: Identification of the differentiation of macrophages from monocytes. (A) Equine MDM were prepared from horse PBMC as described in Materials and Methods and were examined by immunofluorescence assay (IF) using a macrophage specific CD68 mAb. The adherent cells were photographed at 200× magnification. The irregular cytoplasm (grey arrow) and pseudopodia (black arrow) of phagocyte morphology were developed and observed at $48 \mathrm{~h}$ of cultivation under white light. Increasing signals of CD68 were detected by IF (red fluorescence). (B) The adherent cells were infected by EIAV FDDV13 $_{13}$ after 48 of cultivation. Infected cells were detected by indirect
IF using an ElA positive serum and a Texas Red-labeled (a red fluorescent dye) anti-horse lgG mAb 48 hpi.

Additional file 2: mRNA detected by bDNA. The specific oligonucleotide probe sets for the target genes included equine TLR3, TLR7, TLR8, TLR9, IFNa1, IFN $\beta$, ELR1, and $\beta$-actin, which were used with the QuantiGene 2.0 Reagent Systems designed and provided by the manufacturer (Panomics)

Additional file 3: Analysis of the early (Annexin V+/PI-) and late (Annexin $\mathrm{V}+/ \mathrm{PI}+$ ) apoptotic populations of eMDM infected with either EIAV FDDV13 $_{\text {or EIAV }}$ UK3. EMDM infected with either EIAV FDDV13 or EIAV $_{U K 3}$ for $1,3,5$ and 8 days were analyzed for apoptosis by flow cytometry. The eMDM were trypsinized and collected at the indicated time points and washed once with the Binding Buffer. These cells were re-suspended in $100 \mu \mathrm{L}$ Binding Buffer and were stained by adding $5 \mu \mathrm{L}$ AnnexinV and $5 \mu \mathrm{L}$ of $3 \mu \mathrm{M}$ PI. After 15 min incubation at room temperature, apoptotic populations were analyzed. Triplicate wells of cells were examined for each treatment. The results were calculated from the data of three independent experiments.

Additional file 4: The expression of "house-keeping" gene $\beta$-actin in eMDM infected with EIAV or treated with Poly I:C. Cells were infected with either EIAVF $F_{D D V 13}$ or EIAV $V_{U K 3}$ or treated with Poly I:C. The same amount of cells $\left(1 \times 10^{5}\right)$ from each treatment was harvested and mRNA copies of $\beta$-actin in these cells were quantified by real time RT-PCR. NC: negative control of untreated cells.

Additional file 5: Regulation of TLR7, TLR8 and TLR9 expression in

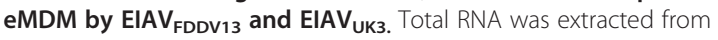
eMDM infected with equal infectious titers of either EIAV $V_{F D D V 13}$ or EIAV $V_{U K 3}$ for various times. The mRNA levels of TLR7, TLR8 and TLR9 were quantified with the bDNA assay. The values of $Y$ axis were treated by Log2. ${ }^{* *} P<0.01$.

Additional file 6: Regulation of IFNa expression in eMDM by

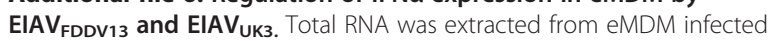
with equal infectious titers of EIAV $\mathrm{FDDV}_{13}$ or EIAV $\mathrm{EKK}_{3}$ for various times. mRNA encoding IFNa1 was quantified with the bDNA assay. The protein expression level of IFNa was measured using an ELISA kit. The values of $Y$ axis were treated by Log2. ${ }^{*} P<0.05,{ }^{* *} P<0.01$.

\section{Abbreviations}

EIAV: Equine infectious anemia virus; eMDM: Equine monocyte-derived macrophages; sELR1: Soluble ELR1; TLR: Toll like receptor; IFN: Interferon; $\mathrm{TCID}_{50}$ : Median tissue culture infective dose method; PRR: Pattern recognition receptors; PAMP: Pathogen associated molecular pattern; FDD: Fetal donkey dermal; PBS: Phosphate-buffered saline; FBS: Fetal bovine serum; RT: Reverse transcriptase activity; RT-PCR: Reverse transcription PCR; bDNA: Branch DNA; ELISA: Enzyme-linked immunosorbent assays.

\section{Competing interests}

The authors declare that they have no competing interests.

\section{Authors' contributions}

JM and SSW performed almost all of the experiments and prepared the figures. YZL, HMW, CD, and XFW conducted the bDNA assay and flow cytometry analysis. HFL and YHW completed the realtime PCR assays. QL completed the immune staining of eMDM. XJW completed part of the analysis of innate immunity activation. JM, JHZ, and XGK conceived of the study and designed experiments. JM, SSW and JHZ prepared the manuscript. All authors read and approved the final manuscript.

\section{Acknowledgments}

We are especially grateful to Dr R. Montelaro of the Center for Vaccine Research at Pittsburgh University for providing the molecular clone of EIAV $_{\text {UK3 }}$. This study was supported by Grant 31372451 and 31222054 from the National Natural Science Foundation of China, Grant 2012ZX10001-008 from the Chinese National Key Programs for Infectious Diseases in China, Grant LBH-Q12001 from Postdoc Foundation of Heilongjiang province, China, and Grant SKLVBP2011 from State Key Laboratory of Veterinary Biotechnology, China. 


\section{Author details}

${ }^{1}$ State Key Laboratory of Veterinary Biotechnology, Harbin Veterinary Research Institute, Chinese Academy of Agricultural Sciences, Harbin, Heilongjiang 150001, China. ${ }^{2}$ Geriatrics Ward, First Hospital of Harbin Medical University, No23 Youzheng Street, Harbin, Heilongjiang 150001, China.

Received: 7 November 2013 Accepted: 23 July 2014

Published: 9 August 2014

\section{References}

1. Leroux C, Cadore JL, Montelaro RC: Equine Infectious Anemia Virus (EIAV): what has HIV's country cousin got to tell us? Vet Res 2004, 35:485-512.

2. Maury W: Monocyte maturation controls expression of equine infectious anemia virus. J Virol 1994, 68:6270-6279.

3. Hammond SA, Raabe ML, Issel CJ, Montelaro RC: Evaluation of antibody parameters as potential correlates of protection or enhancement by experimental vaccines to equine infectious anemia virus. Virology 1999, 262:416-430.

4. Harrold SM, Cook SJ, Cook RF, Rushlow KE, Issel CJ, Montelaro RC: Tissue sites of persistent infection and active replication of equine infectious anemia virus during acute disease and asymptomatic infection in experimentally infected equids. J Virol 2000, 74:3112-3121.

5. Craigo JK, Durkin S, Sturgeon TJ, Tagmyer T, Cook SJ, Issel CJ, Montelaro RC: Immune suppression of challenged vaccinates as a rigorous assessment of sterile protection by lentiviral vaccines. Vaccine 2007, 25:834-845.

6. Ma J, Shi N, Jiang CG, Lin YZ, Wang XF, Wang S, Lv XL, Zhao LP, Shao YM, Kong $X G$, Zhou $J H$, Shen $R X$ : A proviral derivative from a reference attenuated EIAV vaccine strain failed to elicit protective immunity. Virology 2011, 410:96-106.

7. Meng Q, Lin Y, Ma J, Ma Y, Zhao L, Li S, Liang H, Zhou J, Shen R, Zhang X, Shao $Y$ : A pilot study on an attenuated Chinese EIAV vaccine inducing broadly neutralizing antibodies. Arch Virol 2011, 156:1455-1462.

8. Maury W, Wright PJ, Bradley S: Characterization of a cytolytic strain of equine infectious anemia virus. J Virol 2003, 77:2385-2399.

9. Brindley MA, Zhang B, Montelaro RC, Maury W: An equine infectious anemia virus variant superinfects cells through novel receptor interactions. J Virol 2008, 82:9425-9432.

10. Jiang CG, Gao X, Ma J, Lin YZ, Wang XF, Zhao LP, Hua YP, Liu D, Zhou JH: C-terminal truncation of the transmembrane protein of an attenuated lentiviral vaccine alters its in vitro but not in vivo replication and weakens its potential pathogenicity. Virus Res 2011, 158:235-245.

11. Ma J, Jiang C, Lin $Y$, Wang $X$, Zhao L, Xiang W, Shao $Y$, Shen R, Kong $X$, Zhou J: In vivo evolution of the gp90 gene and consistently low plasma viral load during transient immune suppression demonstrate the safety of an attenuated equine infectious anemia virus (EIAV) vaccine. Arch Virol 2009, 154:867-873.

12. Cook RF, Cook SJ, Berger SL, Leroux C, Ghabrial NN, Gantz M, Bolin PS, Mousel MR, Montelaro RC, Issel CJ: Enhancement of equine infectious anemia virus virulence by identification and removal of suboptimal nucleotides. Virology 2003, 313:588-603

13. Cook RF, Cook SJ, Li FL, Montelaro RC, Issel CJ: Development of a multiplex real-time reverse transcriptase-polymerase chain reaction for equine infectious anemia virus (EIAV). J Virol Methods 2002, 105:171-179.

14. Reed $\mathrm{L}$, Muench $\mathrm{H}$ : A simple method of estimating fifty percent endpoints. Am J Hyg 1938, 27:493-497.

15. Lin YZ, Yang F, Zhang SQ, Sun LK, Wang XF, Du C, Zhou JH: The soluble form of the EIAV receptor encoded by an alternative splicing variant inhibits EIAV infection of target cells. PLoS One 2013, 8:e79299.

16. Wu W, Blythe DC, Loyd H, Mealey RH, Tallmadge RL, Dorman KS, Carpenter S: Decreased infectivity of a neutralization-resistant equine infectious anemia virus variant can be overcome by efficient cell-to-cell spread. J Virol 2011 85:10421-10424.

17. Parker LC, Prince LR, Sabroe I: Translational mini-review series on Toll-like receptors: networks regulated by Toll-like receptors mediate innate and adaptive immunity. Clin Exp Immunol 2007, 147:199-207.

18. Baccala R, Hoebe K, Kono DH, Beutler B, Theofilopoulos AN: TLR-dependent and TLR-independent pathways of type I interferon induction in systemic autoimmunity. Nat Med 2007, 13:543-551.
19. Flur K, Allam R, Zecher D, Kulkarni OP, Lichtnekert J, Schwarz M, Beutler B, Vielhauer $\mathrm{V}$, Anders HJ: Viral RNA induces type I interferon-dependent cytokine release and cell death in mesangial cells via melanomadifferentiation-associated gene-5: implications for viral infectionassociated glomerulonephritis. Am J Pathol 2009, 175:2014-2022.

20. Nethe M, Berkhout $B$, van der Kuyl AC: Retroviral superinfection resistance. Retrovirology 2005, 2:52

21. Wildum S, Schindler M, Munch J, Kirchhoff F: Contribution of Vpu, Env, and Nef to CD4 down-modulation and resistance of human immunodeficiency virus type 1-infected T cells to superinfection. J Virol 2006, 80:8047-8059.

22. Haim H, Si Z, Madani N, Wang L, Courter JR, Princiotto A, Kassa A, DeGrace M, McGee-Estrada K, Mefford M, Gabuzda D, Smith AB 3rd, Sodroski J: Soluble CD4 and CD4-mimetic compounds inhibit HIV-1 infection by induction of a short-lived activated state. PLoS Pathog 2009, 5:e1000360.

23. Daar ES, Li XL, Moudgil T, Ho DD: High concentrations of recombinant soluble CD4 are required to neutralize primary human immunodeficiency virus type 1 isolates. Proc Natl Acad Sci U S A 1990, 87:6574-6578

24. Sullivan N, Sun Y, Binley J, Lee J, Barbas CF 3rd, Parren PW, Burton DR, Sodroski J: Determinants of human immunodeficiency virus type 1 envelope glycoprotein activation by soluble CD4 and monoclonal antibodies. J Virol 1998, 72:6332-6338.

25. Zhou Y, Wang X, Liu M, Hu Q, Song L, Ye L, Zhou D, Ho W: A critical function of toll-like receptor-3 in the induction of anti-human immunodeficiency virus activities in macrophages. Immunology 2010, 131:40-49.

26. Kawai T, Akira S: The role of pattern-recognition receptors in innate immunity: update on Toll-like receptors. Nat Immunol 2010, 11:373-384.

27. Kawai T, Akira S: Innate immune recognition of viral infection. Nat Immunol 2006, 7:131-137.

28. Swanson CL, Wilson TJ, Strauch P, Colonna M, Pelanda R, Torres RM: Type I IFN enhances follicular B cell contribution to the T cell-independent antibody response. J Exp Med 2010, 207:1485-1500.

29. Le Bon A, Schiavoni G, D'Agostino G, Gresser I, Belardelli F, Tough DF: Type i interferons potently enhance humoral immunity and can promote isotype switching by stimulating dendritic cells in vivo. Immunity 2001, 14:461-470

30. Zhu J, Huang $X$, Yang Y: Type I IFN signaling on both B and CD4 T cells is required for protective antibody response to adenovirus. J Immunol 2007, 178:3505-3510.

31. Cucak H, Yrlid U, Reizis B, Kalinke U, Johansson-Lindbom B: Type I interferon signaling in dendritic cells stimulates the development of lymph-noderesident T follicular helper cells. Immunity 2009, 31:491-501.

32. King C, Sprent J: Emerging cellular networks for regulation of $\mathrm{T}$ follicular helper cells. Trends Immunol 2012, 33:59-65

33. Craigo JK, Barnes S, Zhang B, Cook SJ, Howe L, Issel CJ, Montelaro RC: An EIAV field isolate reveals much higher levels of subtype variability than currently reported for the equine lentivirus family. Retrovirology 2009, 6:95.

34. Qi X, Wang X, Wang S, Lin Y, Jiang C, Ma J, Zhao L, LV X, Shen R, Wang F, Su Z, Zhou J: Genomic analysis of an effective lentiviral vaccine-attenuated equine infectious anemia virus vaccine EIAV FDDV13. Virus Genes 2010, 41:86-98.

doi:10.1186/s13567-014-0082-y

Cite this article as: Ma et al:: Infection of equine monocyte-derived macrophages with an attenuated equine infectious anemia virus (EIAV) strain induces a strong resistance to the infection by a virulent EIAV strain. Veterinary Research 2014 45:82 